\title{
The cervical spine in patients with psoriatic arthritis: a clinical, radiological and immunogenetic study
}

2nd Divisione di

Medicina

(Unità Reumatologica),

USL N9, Reggio Emilia,

Italy

C Salvarani

P Macchioni

F Rossi

N Capozzoli

R Baricchi

I Portioli

2 Dipartimento di

Radiologia, USL N9,

Reggio Emilia, Italy

T Cremonesi

B Battistel

Laboratorio Patologia

Clinica,

Ospedale Malpighi,

USL N28, Bologna, Italy

W Mantovani

Correspondence to:

Dr Carlo Salvarani,

2nd Divisione di Medicina,

Unità Reumatologica,

Arcispedale S. Maria Nuova,

$\mathrm{V}$ le Umberto $1^{\circ} \mathrm{N} 50$

42100 Reggio Emilia, Italy.

Accepted for publication

8 January 1991

Carlo Salvarani, Pierluigi Macchioni, Tiziana Cremonesi, Wilma Mantovani, Bruna Battistel, Fulvia Rossi, Nicholas Capozzoli, Roberto Baricchi, Italo Portioli

\begin{abstract}
The radiological changes of the cervical spine were evaluated in 57 patients with psoriatic arthritis and were correlated with clinical, radiological, and immunogenetic features of the disease. Forty patients $(70 \%)$ showed radiological evidence of the cervical spine being affected by the disease. Two patterns of cervical spine abnormalities were noted. Fifteen patients $(26 \%)$ had erosive and/or subluxing cervical rheumatoid like lesions; 25 patients $(\mathbf{4 4 \% )}$ had a more frequently reported pattern similar to ankylosing spondylitis. Although subaxial subluxations were the most frequently observed cervical abnormalities $(53 \%)$ in the inflammatory subgroup, none of the patients studied had cord compression. Ankylosing cervical spine disease was the only form of axial involvement in nine $(36 \%)$ of 25 patients with the ankylosing form of psoriatic arthritis. All of these patients had peripheral disease and were B27 negative.

Predictors of cervical spine disease patterns were considered using clinical, demographic, and radiological features and HLA antigens. The results of a multivariate analysis showed that the best predictors of inflammatory cervical spine disease are the presence of HLA-B39 and HLA-DR4 antigens, radiocarpal erosions, and the absence of the HLA-DR5 antigen.
\end{abstract}

Radiological evidence of the cervical spine being affected by the disease is a relatively common finding in patients with psoriatic arthritis, ${ }^{1-12}$ occurring in $35-75 \%$ of patients. In general, a pattern similar to ankylosing spondylitis with syndesmophytes, apophyseal joint ankylosis, and ligamentous calcifications is the most frequent radiological change. ${ }^{2}$ Cervical spine lesions are occasionally reported and are characterised by apophyseal joint erosion, vertebral plate erosion, and atlantoaxial subluxation. ${ }^{578}$ Detailed studies have shown a pattern of cervical spine involvement in patients with psoriatic arthritis identical to that in patients with rheumatoid arthritis. ${ }^{19}$

A genetic predisposition to psoriatic arthritis has been supported by population studies reporting an increased frequency of certain HLA antigens in patients with the disease. Several workers have established an association between HLA-B38 and the peripheral form of psoriatic arthritis ${ }^{13-15}$ and between B27 and the axial form. ${ }^{10}{ }^{14-16}$ HLA-DR4 has been associated with rheumatoid arthritis like disease, ${ }^{14} 17$ severity of disease ${ }^{17}$ and the presence of erosion. ${ }^{10}$

The aim of this study was to investigate radiological changes of the cervical spine in 57 Italian patients with psoriatic arthritis, to confirm the presence of a pattern similar to that in patients with rheumatoid arthritis, and to identify HLA markers for radiological patterns of the ceryical spine.

\section{Materials and methods}

PATIENT POPULATION

Fifty seven consecutive patients with psoriatic arthritis originating from northern Italy were studied. The diagnosis of psoriatic arthritis was based on the presence of an inflammatory seronegative arthropathy in association with psoriasis. Table 1 gives the clinical and demographic features of these patients.

The patients were classified as follows, according to the criteria proposed by Kammer et $\mathrm{al}^{18}$ : group 1 , patients with only asymmetrical, oligoarticular disease; group 2, patients with only symmetrical disease; and group 3, patients with axial disease (with or without peripheral involvement). Axial disease required radiographic evidence of grade III or IV sacroiliitis using the New York criteria ${ }^{19}$ and/or syndesmophytes.

RADIOLOGY

All patients underwent a radiological examina-

Table 1 Demographic and clinical features of the patients with psoriatic arthritis related to the pattern of the cervical spine

\begin{tabular}{|c|c|c|c|c|}
\hline Features & $\begin{array}{l}\text { All patients } \\
\text { with psoriatic } \\
\text { arthritis }(n=57)\end{array}$ & $\underset{(n=15)}{G r o u p} a$ & $\begin{array}{l}\operatorname{Group}_{(n=25)} b \\
\text { a }\end{array}$ & $\begin{array}{l}\text { Group c } \\
(n=I 7)\end{array}$ \\
\hline $\begin{array}{l}\text { Mean (SD) age (years) } \\
\text { Female:male ratio } \\
\text { Mean (SD) age of onset of arthritis (years) } \\
\text { Mean (SD) duration of arthritis (months) } \\
\text { Mean (SD) duration of psoriasis (months) }\end{array}$ & $\begin{array}{l}56(11) \\
29 / 28 \\
47(13) \\
116(95) \\
175(129)\end{array}$ & $\begin{array}{c}56(13) \\
7 / 8 \\
44(14) \\
142(111) \\
150(111)\end{array}$ & $\begin{array}{l}58(11) \\
11 / 14 \\
48(14) \\
114(86) \\
196(139)\end{array}$ & $\begin{array}{l}54(10) \\
11 / 6 \\
46(11) \\
93(89) \\
168(133)\end{array}$ \\
\hline $\begin{array}{l}\text { Number (\%) of patients in clinical subgroup } \\
\text { Asymmetric peripheral disease } \\
\text { Symmetric peripheral disease } \\
\text { Axial } \pm \text { peripheral disease } \\
\text { Family history of psoriasis (\%) } \\
\text { Nail lesions (\%) }\end{array}$ & $\begin{array}{l}\text { (Kammer et al } \\
17(30) \\
16(28) \\
24(42) \\
14 \\
45\end{array}$ & $\begin{array}{c}7(47) \\
3(20) \\
5(33) \\
7 \\
53\end{array}$ & $\begin{array}{l}5(20) \\
5(20) \\
15(60) \\
20 \\
32\end{array}$ & $\begin{array}{l}5(29) \\
8(47) \\
4(23) \\
12 \\
59\end{array}$ \\
\hline
\end{tabular}


tion of the hands, wrists, feet, cervical, thoracic and lumbar spine, and sacroiliac joints. All radiographs were reviewed independently by at least three of these authors.

Cervical radiographs included lateral flexion and extension, open mouth odontoid, and anteroposterior views. Plain film tomography was performed when the cervical structures could not be clearly delineated. Atlantoaxial subluxation was defined as an atlantodens interval of more than $4.5 \mathrm{~mm}$. Odontoid erosions were considered when changes in the normal contour of the anterior, superior, and posterior aspect of the odontoid process were present.

Vertical penetration had occurred if MacGregor's line was more than $4.5 \mathrm{~mm}$ caudad to the tip of the dens on a lateral radiograph, or if the bimastoid line on an anteroposterior film was more than $1 \mathrm{~mm}$ caudad to the dens. Subaxial subluxation was diagnosed when the relationship between the body or facet joints of the vertebrae below the second cervical vertebra were displaced more than $3.5 \mathrm{~mm}$. The presence of apophyseal joint or disc space narrowing, ankylosis, and ligamentous calcification was also noted. Radiographs of the peripheral joints were evaluated for the presence of erosions, joint space narrowing, ankylosis, and alignment abnormalities.

The patients were classified into the following three groups based on cervical spine radiographs according to Blau and Kaufman ${ }^{1}$ : group a, patients with evidence of inflammatory cervical spine involvement (erosions and/or subluxations) in the absence of ankylosis or ligamentous calcification; group $b$, patients with cervical ankylosing disease (apophyseal joint sclerosis or fusion, anterior or posterior calcification, and/or syndesmophyte formation); and group c, patients with normal cervical spine radiographs. $\mathrm{Cl}-2$ erosion or subluxation may be present in groups $a$ and $b$; when it was the only abnormality the patient was classified as group a.

\section{HLA TYPING}

The healthy control group consisted of a pool of 242 blood donor volunteers from the same geographical area of Italy.

The determination of class I MHC antigen (HLA-A, B, C) and class II (HLA-DR, DQ) was performed using a modification of the two stage National Institute of Health complement microcytotoxicity test. ${ }^{20}$ Lymphocytes were typed using a panel of 180 antisera from the 8th and 9th Histocompatibility Workshops recognising about 50 different specificities.

\section{STATISTICAL ANALYSIS}

Analysis was carried out using the SPSS programs. The $\chi^{2}$ test with Yate's correction and Fisher's exact test were used to compare the frequencies of HLA antigens and for noncontinuous variables. $p$ Values were corrected for the number of antigens tested. Student's $t$ test was used for comparing continuous variables. Relative risks were calculated using the Woolf method. Relative risk was estimated by the method of Haldane ${ }^{21}$ if required.
Radiological groups a (inflammatory cervical spine involvement) and $b$ (cervical ankylosing disease) were compared in a multivariate discriminant analysis to see if a set of variables (clinical, demographical, radiological, and HLA antigens) considered collectively could discriminate between them.

\section{Results}

CLINICAL FINDINGS

Table 1 gives the clinical and demographic features of the 57 patients. Of the 24 patients included in Kammer's group 3, only one had axial involvement without peripheral disease. Only one patient had arthritis mutilans. Although a shorter duration of arthritis was found in patients without cervical spine abnormalities (group c), this difference did not reach statistical significance. No significant differences were observed between the three radiological subgroups when the other variables investigated were compared. Axial disease was more frequently observed in patients in group $b$ than in group a (60 v 33\%, $\mathrm{p}=\mathrm{NS})$, whereas peripheral asymmetrical joint involvement was more frequent in patients in group a (47 v20\%, $p=N S$ ).

Twenty three patients $(40 \%)$ had symptoms of inflammatory cervical disease (neck pain or stiffness) and fourteen patients (25\%) presented with limited neck motion. There were no significant differences in the distribution of symptoms of cervical spine disease between the radiological subgroups $a$ and $b$.

\section{CERVICAL SPINE ABNORMALITIES}

Radiographic abnormalities of the cervical spine were found in $70 \%$ of the patients. Table 2 shows that the frequencies of atlantoaxial subluxation and odontoid erosions were 23 and $12 \%$.

Table 3 shows the percentage of cervical spine abnormalities in patients of groups $a$ and $b$. Atlantoaxial subluxation and odontoid erosions were more frequently observed in group a patients than in group b $(40 v 28 \%$ and $33 v$ $8 \%$ ), but these differences were not significant. The most common abnormality in group a was subaxial subluxation (53\%), and the frequency of this reached statistical significance when compared with the ankylosing group $(p=0 \cdot 001)$.

Table 2 Radiological abnormalities of the cervical spine in the 57 patients with psoriatic arthritis

\begin{tabular}{lc}
\hline Radiological abnormality & $\begin{array}{l}\text { Number of patients } \\
(\%)\end{array}$ \\
\hline Atlantoaxial subluxation & $13(23)$ \\
Odontoid erosions & $7(12)$ \\
Vertical penetration & $1(2)$ \\
Facet joint & $4(7)$ \\
$\quad$ Narrowing & $0(0)$ \\
Fusion & $7(12)$ \\
Subaxial spine & $20(35)$ \\
Fusion & $9(16)$ \\
Narrowing & $11(19)$ \\
Subluxation & $17(30)$ \\
Syndesmophytes & $3(5)$ \\
Ligamentous calcification & $1(2)$ \\
$\quad$ Anterior & Posterior \\
Anterior and posterior &
\end{tabular}


Table 3 Radiological abnormalities of the cervical spine in patients with erosive (and/or subluxing) and ankylosing cervical disease

\begin{tabular}{|c|c|c|c|}
\hline $\begin{array}{l}\text { Radiological } \\
\text { abnormality }\end{array}$ & $\begin{array}{l}\text { Number of } \\
\text { patients }(\%) \text { : } \\
\text { group } a \\
(n=15)\end{array}$ & $\begin{array}{l}\text { Number of } \\
\text { patients }(\%) \text { : } \\
\text { group } b \\
(n=25)\end{array}$ & $P$ Value $^{*}$ \\
\hline $\begin{array}{l}\text { Atlantoaxial subluxation } \\
\text { Odontoid erosions } \\
\text { Vertical penetration }\end{array}$ & $\begin{array}{l}6(40) \\
5(33) \\
1(7)\end{array}$ & $\begin{array}{l}7(28) \\
2(8) \\
0(0)\end{array}$ & $\begin{array}{l}\text { NS } \\
\text { NS }\end{array}$ \\
\hline $\begin{array}{l}\text { Facet joint } \\
\text { Narrowing } \\
\text { Fusion }\end{array}$ & $\begin{array}{l}3(20) \\
0(0)\end{array}$ & $\begin{array}{l}1(4) \\
0(0)\end{array}$ & $\begin{array}{l}\text { NS } \\
\text { NS }\end{array}$ \\
\hline $\begin{array}{l}\text { Subaxial spine } \\
\text { Fusion } \\
\text { Narrowing } \\
\text { Subluxation } \\
\text { Syndesmophytes }\end{array}$ & $\begin{array}{l}0(0) \\
4(27) \\
8(53) \\
0(0)\end{array}$ & $\begin{array}{r}7(28) \\
12(48) \\
1(4) \\
11(44)\end{array}$ & $\begin{array}{l}0.05 \\
\text { NS } \\
0.001 \\
0.002\end{array}$ \\
\hline $\begin{array}{l}\text { Ligamentous calcification } \\
\text { Anterior } \\
\text { Posterior } \\
\text { Anterior and posterior }\end{array}$ & $\begin{array}{l}0(0) \\
0(0) \\
0(0)\end{array}$ & $\begin{array}{c}17(61) \\
3(12) \\
1(4)\end{array}$ & $\begin{array}{l}0.001 \\
\text { NS } \\
\text { NS }\end{array}$ \\
\hline
\end{tabular}

${ }^{*} \mathrm{NS}=$ not significant.

Table 4 HLA antigens in patients with total psoriatic arthritis compared with control subjects. Values are percentage of patients in which antigen occurs

\begin{tabular}{|c|c|c|c|c|}
\hline $\begin{array}{l}\text { HLA } \\
\text { antigen }\end{array}$ & $\begin{array}{l}\text { Control subjects } \\
(n=242)\end{array}$ & $\begin{array}{l}\text { Patients with } \\
\text { psoriatic arthritis } \\
(n=57)\end{array}$ & p Value & $\begin{array}{l}\text { Relative } \\
\text { risk }\end{array}$ \\
\hline $\begin{array}{l}\text { A1 } \\
\text { B5 } \\
\text { B13 } \\
\text { B17 } \\
\text { B27 } \\
\text { B38 } \\
\text { B39 } \\
\text { Cw6 } \\
\text { DR4 } \\
\text { DR5 } \\
\text { DR7 } \\
\text { DQw3 }\end{array}$ & $\begin{array}{r}22 \cdot 4 \\
26 \cdot 9 \\
6 \cdot 2 \\
8 \cdot 7 \\
1 \cdot 2 \\
3.7 \\
4 \cdot 1 \\
10 \cdot 7 \\
14 \cdot 4 \\
34 \cdot 3 \\
32 \cdot 2 \\
47 \cdot 5\end{array}$ & $\begin{array}{r}31 \cdot 6 \\
12 \cdot 2 \\
8 \cdot 7 \\
12 \cdot 3 \\
7 \cdot 3 \\
19 \cdot 3 \\
8 \cdot 7 \\
10 \cdot 5 \\
8 \cdot 7 \\
14 \cdot 0 \\
26 \cdot 3 \\
31 \cdot 6\end{array}$ & $\begin{array}{l}\text { NS } \\
0.05 \dagger \\
\text { NS } \\
\text { NS } \\
0.05 \dagger \\
0.0001 \ddagger \\
\text { NS } \\
\text { NS } \\
\text { NS } \\
0.01 \dagger \\
\text { NS } \\
\text { NS }\end{array}$ & $\begin{array}{l}1.7 \\
0.4 \\
1.5 \\
1.5 \\
6.0 \\
6.2 \\
2.2 \\
1.0 \\
0.6 \\
0.3 \\
0.7 \\
0.5\end{array}$ \\
\hline
\end{tabular}

NS $=$ not significant.

fCorrected $p$ value not significant.

fCorrelation maintaining significance after correcting for number of antigens tested.

Table 5 HLA antigens in patients with erosive (and/or subluxing) cervical spine disease compared with control subjects. Values are percentage of patients in which antigen occurs

\begin{tabular}{lllll}
\hline $\begin{array}{l}\text { HLA } \\
\text { antigen }\end{array}$ & $\begin{array}{l}\text { Control subjects } \\
(n=242)\end{array}$ & $\begin{array}{l}\text { Erosive cervical spine disease } \\
(n=15)\end{array}$ & $p$ Value & $\begin{array}{l}\text { Relative } \\
\text { risk }\end{array}$ \\
\hline A1 & 22.4 & 33.3 & NS & 1.7 \\
B5 & 26.9 & 13.3 & NS & 0.4 \\
B13 & 6.2 & 6.7 & NS & 1.0 \\
B17 & 8.7 & 20.0 & NS & 2.6 \\
B27 & 1.2 & 6.7 & NS & 5.6 \\
B38 & 3.7 & 13.3 & NS & 3.9 \\
B39 & 4.1 & 13.3 & NS & 3.6 \\
Cw6 & 10.7 & 20.0 & NS & 2.1 \\
DR4 & 14.4 & 20.0 & $0.02 \dagger$ & 1.5 \\
DR5 & 34.3 & 0.0 & NS & $0.06 *$ \\
DR7 & 32.2 & 33.3 & NS & 1.0 \\
DQw3 & 47.5 & 26.7 & & 0.4 \\
\hline
\end{tabular}

NS = not significant.

${ }^{*}$ Relative risk was estimated by the method of Haldane.

fCorrected $p$ value not significant.

Table 6 HLA antigens in patients with ankylosing cervical spine disease compared with control subjects. Values are percentage of patients in which antigen occurs

\begin{tabular}{|c|c|c|c|c|}
\hline $\begin{array}{l}\text { HLA } \\
\text { antigen }\end{array}$ & $\begin{array}{l}\text { Control subjects } \\
(n=242)\end{array}$ & $\begin{array}{l}\text { Ankylosing cervical spine disease } \\
(n=25)\end{array}$ & p Value & $\begin{array}{l}\text { Relative } \\
\text { risk }\end{array}$ \\
\hline $\begin{array}{l}\text { A1 } \\
\text { B5 } \\
\text { B13 } \\
\text { B17 } \\
\text { B27 } \\
\text { B38 } \\
\text { B39 } \\
\text { Cw6 } \\
\text { DR4 } \\
\text { DR5 } \\
\text { DR7 } \\
\text { DQw3 }\end{array}$ & $\begin{array}{r}22 \cdot 4 \\
26 \cdot 9 \\
6 \cdot 2 \\
8 \cdot 7 \\
1 \cdot 2 \\
3 \cdot 7 \\
4 \cdot 1 \\
10 \cdot 7 \\
14 \cdot 4 \\
34 \cdot 3 \\
32 \cdot 2 \\
47 \cdot 5\end{array}$ & $\begin{array}{r}32 \cdot 0 \\
12 \cdot 0 \\
12 \cdot 0 \\
8 \cdot 0 \\
8 \cdot 0 \\
20 \cdot 0 \\
0 \cdot 0 \\
12 \cdot 0 \\
4 \cdot 0 \\
24 \cdot 0 \\
16 \cdot 0 \\
20 \cdot 0\end{array}$ & $\begin{array}{l}\text { NS } \\
\text { NS } \\
\text { NS } \\
\text { NS } \\
\text { NS } \\
0.001 \ddagger \\
\text { NS } \\
\text { NS } \\
\text { NS } \\
\text { NS } \\
\text { NS } \\
0.02 \dagger\end{array}$ & $\begin{array}{l}1.7 \\
0.4 \\
2.1 \\
0.9 \\
6.9 \\
6.5 \\
0.4^{*} \\
1.1 \\
0.3 \\
0.6 \\
0.4 \\
0.3\end{array}$ \\
\hline
\end{tabular}

Group b patients had a significantly increased incidence of anterior ligamentous calcification (61 $v 0 \%, \mathrm{p}=0.001)$, subaxial fusion $(28 v 0 \%$, $\mathrm{p}=0.05)$, and syndesmophytes (44 $v 0 \%$, $\mathrm{p}=0.002$ ) compared with group $\mathrm{a}$.

In nine $(36 \%)$ of the 25 group b patients syndesmophytes were found in only the cervical spine, and these patients had normal sacroiliac joints.

\section{PERIPHERAL RADIOLOGICAL ABNORMALITIES}

Erosions at radiocarpal joints were more frequently observed in group a patients than in group b (40 $v 24 \%, \mathrm{p}=\mathrm{NS})$. The same low incidence of wrist fusion was observed in group $a$ and $b$ patients $(6.7$ and $8.0 \%$, respectively); none of the patients in group $c$ presented this radiological feature.

\section{HLA FINDINGS}

Table 4 shows the distribution of HLA antigens in our patients compared with normal controls. The total group showed a significant increase in the frequency of B27 and B38, and a reduction of B5 compared with healthy controls. After correction of the $p$ value for the number of antigens tested, only the frequencies of the B38 antigen remained significant. No association between DR or DQw antigens was shown. Comparisons between each of Blau and Kaufmann's cervical spine radiological groups ${ }^{1}$ and normal controls showed an increased frequency of B38 in group b (table 6) and B39 in group $(21 \cdot 4 v 4 \cdot 1 \%, p=0.05$, relative risk $=6 \cdot 3)$. DR5 and DQw 3 were decreased in group a and $b$, respectively. Tables 5 and 6 show that only the increased frequency of $\mathrm{B} 38$ in group $b$ remained significant after correction of the $p$ value.

When intergroup comparisons were made, there were no differences in the distribution of HLA antigens between groups a and b; DR4 was increased in group a patients compared with group b $(20 v 4 \%)$, but the difference was not significant. B27 was absent in the nine patients with only cervical syndesmophytes and normal sacroiliac joints.

\section{RESULTS OF DISCRIMINANT ANALYSIS}

Discriminant analysis was used to see if a set of clinical, demographic, and radiological (excluding cervical spine abnormalities) variables and HLA antigens were useful in discriminating between groups $a$ and $b$.

We found a four variable (HLA-B39, HLADR4, HLA-DR5 and radiocarpal erosions) discriminant function which correctly classified $77.5 \%$ of the patients (Wilks lambda $=0.740$; $\chi^{2}=10 \cdot 80 ; p=0 \cdot 02$ ). This function is:

$$
\begin{gathered}
\text { IP3 }=-7 \cdot 12+0 \cdot 77 \text { (radiocarpal erosions) }+2 \cdot 78 \\
(\text { HLA-B39) }+1 \cdot 83(\text { HLA-DR4) } \\
-1 \cdot 67(\text { HLA-DR5) }
\end{gathered}
$$

where the variables radiocarpal erosions, B39, DR4, and DR5 take a value of unity if the patient is positive for the antigen or presented erosions, and the value two if the patient is 
negative for the antigen or erosions. It was found that adding HLA-B27 and sacroiliitis did not increase the predictive power of these variables. None of the other continuous variables evaluated enhanced the ability to discriminate between groups $a$ and $b$.

The discriminant function was found to misclassify five patients (33\%) of group a and four patients of group b (16\%). A patient may be classified by inserting the respective parameters in the above equation and assigned to group a if the value of IP3 is negative and to group $b$ if it is positive. Thus, the equation will tend to assign an individual to group a if the B39 or DR4 antigens and/or radiocarpal erosions are present and DR5 is absent. A patient will be assigned to group b if DR5 is present and B39, DR4 and/or radiocarpal erosions are absent.

\section{Discussion}

This study confirms the high frequency $(70 \%)$ of radiological cervical spine involvement in patients with psoriatic arthritis observed
previously. ${ }^{2}{ }_{211}$

According to Blau and Kaufman, ${ }^{1}$ two patterns of cervical spine abnormalities are observed. Fifteen patients (26\%) had erosive and/or subluxing cervical rheumatoid arthritis like lesions, whereas 25 patients ( $44 \%$ ) presented the more frequently reported pattern which is similar to that seen in ankylosing spondylitis. In our series there is also high frequency of atlantoaxial subluxation ( $23 \%$ in our study; $18 \%$ in the Blau and Kaufman series ${ }^{1}$ ), although a lower occurrence of odontoid erosions (12 v $43 \%$ ) is seen here. A similar low incidence of odontoid erosions (12\%) was reported by Lassoued et $a l^{9}$ in their series of 56 patients with psoriatic arthritis. Early odontoid erosions can be difficult to detect on standard plain radiographs; tomographies were performed when the odontoid process was not clearly delineated. Progressive erosion of the odontoid process may determine osteolysis leading to atlantoaxial subluxation, but in our study the association between the two lesions was observed in only two patients.

Although subaxial cervical subluxations have been occasionally described in patients with rheumatoid arthritis, this lesion occurred in $16 \%$ of our patients, less than observed by Blau and Kaufmann (28\%). ${ }^{1}$ However, in our study subaxial cervical subluxation was the most frequent and characteristic abnormality (53\%) of group a patients, identifying a subgroup of patients with psoriatic arthritis with inflammatory cervical spine disease occurring in the absence of ankylosis. According to Blau and Kaufman, ${ }^{1}$ atlantoaxial subluxation and odontoid erosions were also observed more frequently in group a patients than in group b (table 3), although the differences in our study were not significant.

Subaxial cervical subluxation has been only occasionally reported in patients with psoriatic arthritis and only one patient has presented with myelopathy. ${ }^{7}$ Blau and Kaufman ${ }^{1}$ reported neurological complications in $14 \%(3 / 21)$ of their patients with psoriatic arthritis with involvement of the cervical spine. Although there was a high percentage of group a patients with subaxial subluxations in our study, none of these patients had cord compression. Interestingly, Suarez-Almazor and Russell ${ }^{8}$ showed that $35 \%$ of patients with spondylitis and peripheral arthritis (primary ankylosing spondylitis or ankylosing spondylitis associated with a secondary disorder, including psoriatic arthritis) had anterior atlantoaxial subluxation compared with no patients in a control group of 21 patients with ankylosing spondylitis with only axial involvement. Our study also confirms this association, showing this complication in $29 \%$ (7/24) of the patients with psoriatic spondylitis and peripheral arthritis. All our patients with anterior atlantoaxial subluxation or with other features of rheumatoid like inflammatory cervical spine involvement presented peripheral disease.

Despite the different radiological features, there was no difference between the two groups in the symptoms of spinal disease and in spinal mobility.

Our study confirms the previously reported increased frequency of the HLA-B38 antigen in Italian patients with psoriatic arthritis. ${ }^{13-15}$ The frequency of the HLA-B27 antigen is low in our control population (1.2\%) from the same geographical area (Emilia Romagna). This low occurrence of B27 in the Emilia Romagna population has been confirmed by another study in the same area. ${ }^{22}$ The four patients carrying the B27 antigen had sacroiliitis, confirming the known association between this antigen and psoriatic spondylitis. However, ankylosing cervical spine disease was the only form of axial involvement in nine (36\%) of our 25 group $b$ patients and none of these carried the B27 antigen. All of these nine patients had peripheral arthritis and radiologically normal sacroiliac joints. Our data suggest that the cervical spine may be the only target of psoriatic spondylitis, especially in B27 negative patients with peripheral arthritis.

We did not find any association with DR4 in the patients of radiological groups a or $b$. However, when intergroup comparisons were made, DR4 occurred with a higher frequency in patients with inflammatory cervical spine disease compared with patients with an ankylosing pattern, although the difference was not significant.

We can confirm the presence of two subsets of cervical spine involvement in patients with psoriatic arthritis: an erosive or subluxing spine disease and an ankylosing disease. The first seems to be associated, as shown by multivariate analysis, with the presence of radiocarpal erosion, B39 and DR4 antigens, and with the absence of DR5, and is rarely complicated by cord compression. The second may be the only manifestation of axial involvement in B27 negative patients with psoriatic arthritis and peripheral disease.

The authors thank Professor V. Wright for his critical review of the manuscript, Ms Rita Farella for clinical assistance in the course of the study, and Ms Jaqueline Costa for manuscript preparation. 
1 Blau R H, Kaufman R L. Erosive and subluxing cervical spine disease in patients with psoriatic arthritis. $\mathcal{F}$ Rheumatol 1987; 14: 111-7.

2 Lambert J R, Wright V. Psoriatic spondylitis: a clinical and radiological description of the spine in psoriatic arthritis. Qf Med 1977; 184: 411-25.

3 Kaplan D, Plotz C M, Nathanson L, et al. Cervical spine in psoriasis and in psoriatic arthritis. Ann Rheum Dis 1964; 23: $50-6$.

4 Jajic I. Radiological changes in the sacro-iliac joints and spine of patients with psoriatic arthritis and psoriasis. Ann Rheum of patients with psori

5 Killebrew K, Gold R H, Sholkoff S D. Psoriatic spondylitis. Diagnostic Radiology 1973; 108: 9-16.

6 McEwen C, DiTata D, Leng C, et al. Ankylosing spondylitis and spondylitis accompanying ulcerative colitis, regional enteritis, psoriasis, and Reiter's disease: a comparative study, Arthritis $R$ heum $1971 ; 14: 291-318$.

7 Fam A G, Cruickshank B. Subaxial cervical subluxation and cord compression in psoriatic spondylitis. Arthritis Rheum 1982; 25: 101-6.

8 Suarez-Almazor $\dot{M}$ E, Russell A S. Anterior atlantoaxial subluxation in patients with spondyloarthropathies: association with peripheral disease. $\mathcal{f}$ Rheumatol 1988; 15 : 973-5.

9 Lassoued S, Hamidou M, Fournie B. Fournie A. Cervical spine involvement in psoriatic arthritis. $\mathcal{F}$ Rheumatol 1989; 16: 251-2

10 McHugh N J, Laurent M R, Treadwell B L J, Tweed J M, Dagger J. Psoriatic arthritis: clinical subgroups and histocompatibility antigens. Ann Rheum Dis 1987; 46: 184-8.

11 Hanly J G, Russell M L, Gladman D D. Psoriatic spondyloarthropathy: a long term prospective study. Ann Rheum Dis 1988; 47: 386-93.
12 Peterson C C, Jr, Silbiger M L. Reiter's syndrome and psoriatic arthritis: their roentgen spectra and some interesting similarities. Am $\mathcal{F}$ Roentgenol 1967; 101: 860-71.

13 Espinosa L R, Vasey F B, Oh J H, et al. Association between HLA-Bw38 and peripheral psoriatic arthritis. Arthritis Rheum 1978; 21: 72-5.

14 Gladman D D, Anhorn K A B, Schachter R K, Mervart H. HLA antigens in psoriatic arthritis. $\mathcal{F}$ Rheumatol 1986; 13: 586-92.

15 Salvarani C, Macchioni P L, Zizzi F, et al. Clinical subgroups in Italian patients with psoriatic arthritis. Clin Exp Rheumatol 1989; 7: 391-6.

16 Metzger A L, Morris R I, Bluestone R, et al. HLAW 27 in psoriatic arthropathy. Arthritis Rheum 1975; 18: 111-5.

17 Gerber L H, Murray C L, Perlman S G, et al. Human lymphocyte antigens characterizing psoriatic arthritis and its subtypes. $\mathcal{F}$ Rheumatol 1982; 9: 703-7.

18 Kammer G M, Soter N A, Gibson D J, et al. Psoriatic arthritis: a clinical, immunologic and HLA study of 100 patients. Semin Arthritis Rheum 1979; 9: 79-95.

19 Bennet $\mathbf{P} \mathbf{H}$, Burch $\mathrm{T}$ A. New York symposium on population studies in the rheumatic disease. New diagnostic criteria. Bull Rheum Dis 1967; 17: 453-8.

20 Terasaki P, McClelland J D. Microdroplet assay of human serum cytotoxins. Nature 1964; 204: 998-1000.

21 Haldane J B S. The estimation and significance of the logarithm of a ratio of frequencies. Ann Hum Genet 1955; 20: 309-11.

22 Savi M, Neri T N, Asinari G. Studio delle frequenze geniche e delle associazioni gametiche degli $\mathrm{Ag}$ HLA nella popolazone del Parmense. Ateneo Parmense 1980; 51: 411-5. 